\title{
Employee Performance Appraisal System Using Adaptive Neuro Fuzzy Inference System (Anfis): A Case Study of Amik Pakarti Luhur
}

\author{
Reza Sulistyawan ${ }^{1}$, Mohammad Syafrullah $^{2}$, HadidtyoWisnu Wardani $^{3}$, Novian \\ Hendrianto ${ }^{4}$ \\ Master Program in Computer Science, Information System Technology, Budi Luhur University \\ Jl. Raya Ciledug, North Petukangan, Kebayoran Lama, South Jakarta 12260.
}

Reza.sulistyawan@gmail.com,mohammad.syafrullah@budiluhur.ac.id,Hadidtyowardani@gmail.com,vhieyan@gmail.com

$* * * * * * * * * * * * * * * * * * * * * * * *$

\section{Abstract:}

Employee performance indicates the result of work from employee in conducting the job based on competence, manner, and motivation. In evaluating employee performance, there are many factors, including loyalty, responsibility, discipline, integrity, team work, and leadership factors. Employee roles in advancing the organization is needed because without a good performance, the organization cannot achieve its objectives well. In AMIK PakartiLuhurTangerang, employee performance evaluationis done subjectively from the result of meeting, hence, the result of evaluation is not accurate. The samples is done by purposive sampling technique, which is the questionnaire is given to respondents. Employee Performance Evaluation Model is made with Adaptive Neuro Fuzzy Inference System (ANFIS) Sugeno method and Toolbox Matlab 8.2 R2013b.To ensure that the system meet the minimum standard quality, thus, the system use Software Quality Assurance (SQA) in evaluating software quality.The conclusion from employee performance evaluation model has a good level of accuracy.

Keyword: Employee Performace, Adaptive Neuro Fuzzy Inference System (ANFIS) Sugeno Method, Matlab R2013b, SQA Method.

$* * * * * * * * * * * * * * * * * * * * * * * *$

\section{INTRODUCTION}

Employee performance evaluation (EPV) becomes more important for management in conducting evaluation towards the company's achievement and business plan in the future. Performance indicates of what an employee has been done to influence the number of actions and ideas to company. Many people think that the employee, who has a higher intelligence, has more successful in completing the job. Emotional intelligence assists $80 \%$ in determining someone's success, whereas other $20 \%$ comes from IQ (Intelligence Quotient) [1].

Problems encountered in evaluating employee performancein AMIK PakartiLuhurTangerang is evaluation done subjectively from the result of meeting, hence, the result of evaluation is not accurate. Therefore, this research will discuss about EPV application system model in accordance with the EPV guidelines in AMIK PakartiLuhur in 2010 with its variable, which are employee's responsibility, discipline, integrity, using Adaptive Neuro Fuzzy Inference System (ANFIS) Sugeno method and software that will be used is Matlab 8.2 (R2013b).

In this research, develop EPV model with ANFIS Sugeno model in case to increasing the accuracy and effectiveness in operating EPV process in AMIK PakartiLuhurTangerang in accordance with reliable fuzzy logic. 


\section{THEORETICAL REVIEW}

\subsection{Employee Performance Evaluation (EPV)}

Performance evaluation (PE) is the assessment process on how wellthe employees do their job as compared to set of standards and then communicate those information to employees [3]. The same thing happened with the previous research was conducted by Pathania\& Pathak, whose PE as the device used to measure standards as set by human resources management[4].

Standard is needed in evaluating performance to identify what must employees need to understand and how they do work. In the implication of $\mathrm{PE}$, it assumesthat employees understand the standard used on their work style, give feedback, development, and intensive to employees in order to reduce unfavorable work result and continue favorable result.

\subsection{Fuzzy logic}

Fuzzy logic is one of component to form soft computing. The basis of fuzzy logic is the theory of fuzzy sets. In theory of fuzzy sets, the role of the degree of association in a set as the determinant of the existence of fundamental is very important. Association value or degree of association or membership function becomes the main characteristic from rational with fuzzy logic[2].

\subsection{Sugeno Method}

Fuzzy logic inference system use Sugeno method has the characteristic thata consequent is not a part of logic fuzzy set, but is a linier equation with variable that suits with its input variable [6]. This method was first introduced by Takagi-Sugeno Kang in 1985.

\subsection{Matlab Software}

Matlab is a software with high capability in computing sector. Currently, programming languages are not only required to have advantages in computing aspecs, but also required to have good visualization. Matlab is able to integrate computing, visualizing, and programming. In giving a clear picture of an object, Matlab is able to change the object without changing the program [5]. One of the features found in Matlab to make a representation of an object is Guide.Guide or Graphical User Interface GUI Builder is one of the abilities from Matlab that was built with a display such as buttons, static text, text boxes, check boxes, and menus.

\subsection{Software Quality Assurance (SQA)}

SQA is an activity that takes place in the development of software and maintains the quality of software itself. Three important things in the definition of quality:
1. Software requirement, the basis of quality measurement.

2. Standard that used in determining criteria of how software is engineered.

3. There are numbers of implicit demand that are not adequate considered, but still need attention.

\section{RESEARCH DESIGN}

This research uses quantitative method to get the data, the author will conduct direct observation and will take questionnaires that previously existed.

A. Steps of The Research Process

1. Identify the Problems

Research initialization and problem formulation.

2. Literature Study and Research Review Learn literature study and research review.

3. Data Collection Make observation with related parties.

4. Feasibility Study Identify the feasibility of the system both technically and organizationally.

5. System Analysis

Analyze the system for user needs both functionally and non-functionally.

6. System Planning

System planning to describe the systems meet the needs.

7. Encoding

Encoding in accordance with system planning into the programming language.

8. System Test and Evaluation

System test is done to validate the quality of system test compared to the result of analysis and planning.

9. Implementation

Implementation phase from previous planning.

B. Obtain Samples Method

The sample selection process is done through direct observation. The sample selection is based on January to June 2018 and July to December 2018. Samples in this research are 30 employees in AMIK PakartiLuhur.

\section{Research Instruments}

To obtain the data and information in determining EPV, it is done by retrieving the data that has already owed.

D. Analysis Method

To build system application model that is capable to implement ANFIS such as descriptive analysis, which the employee performance score is got by determining 15 employees for every 6 months in 2018, included Responsibility, Discipline and Integrity. And inferential 
analysis, included test hybrid algorithm and back propagation.

\section{E. Test The Reliability of GUI}

To ensure that the software has a minimum standard quality. Therefore, one of the method to measure the software quality quantitatively used SQA method.

Tabel 1.Measurement SQA method, [5]

\begin{tabular}{|c|l|l|c|}
\hline No & \multicolumn{1}{|c|}{ Metrics } & \multicolumn{1}{|c|}{ Description } & Weight \\
\hline $\mathbf{1}$ & Auditability & $\begin{array}{l}\text { Fulfill the standard } \\
\text { or not }\end{array}$ & 0.1 \\
\hline $\mathbf{2}$ & Accuracy & Computing accuracy & 0.15 \\
\hline $\mathbf{3}$ & Completeness & Completeness & 0.1 \\
\hline $\mathbf{4}$ & $\begin{array}{l}\text { Error } \\
\text { Tolerance }\end{array}$ & Tolerance to error & 0.1 \\
\hline $\mathbf{5}$ & $\begin{array}{l}\text { Execution } \\
\text { Efficiency }\end{array}$ & $\begin{array}{l}\text { Performance } \\
\text { execution }\end{array}$ & 0.1 \\
\hline $\mathbf{6}$ & Operability & Easy to operate & 0.15 \\
\hline $\mathbf{7}$ & Simplicity & Understandability & 0.15 \\
\hline $\mathbf{8}$ & Training & $\begin{array}{l}\text { Easy to learn Help } \\
\text { facilities }\end{array}$ & 0.15 \\
\hline
\end{tabular}

\section{RESULT DISCUSSION \\ ANALYSIS}

AND

4.1. Adaptive Neuro Fuzzy Inference System (ANFIS) Simulation

There are steps for ANFIS to EPV, as follows:

1. Load Data and Testing Data

Load Data is done by taking the file that previously saved.

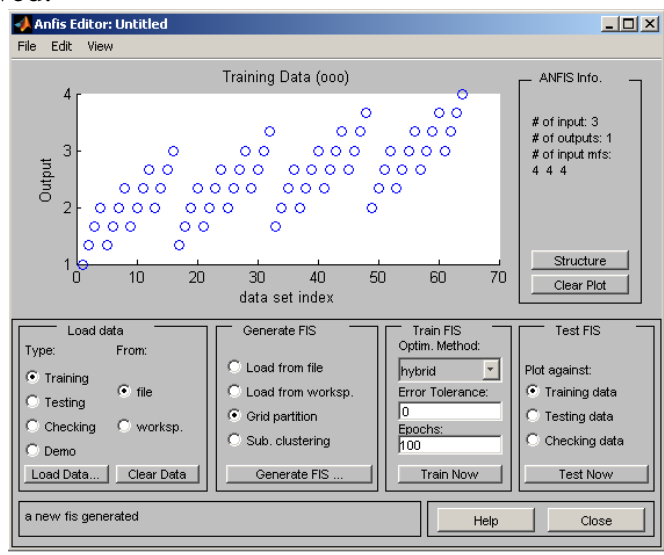

Figure 1. load data training

After the data is loaded, the data will be tested.

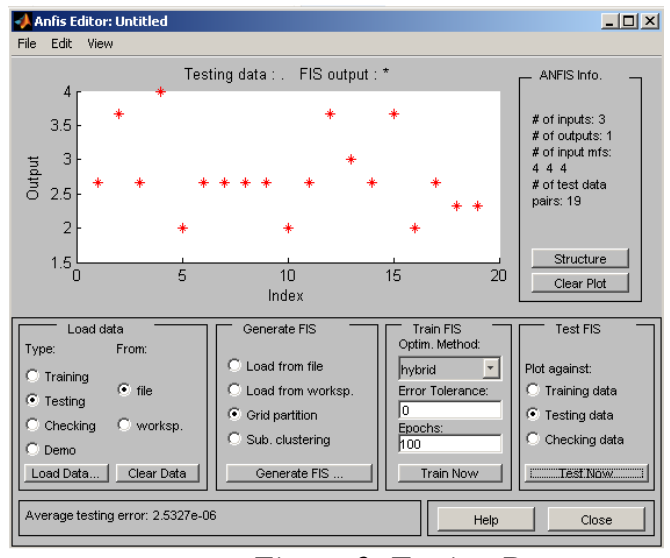

Figure 2. Testing Data

\section{Generate FIS}

Generate the structure from FIS model. In this research, membership function that will be used [4 4 4] in trimf curve, trapmf, gbellmf, and gaussmf.

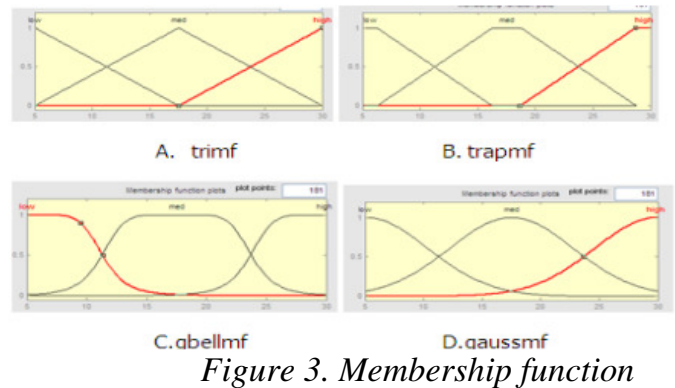

This research use hybrid algorithm (Back propagation + Least Square Estimation) and back propagation algorithm and output parameters from membership functions are constant output.

3. Train FIS

This step use predetermined algorithm, so that it would be better to know the smallest error rate on ANFIS.

4. Test FIS

Using FIS that previously created,

A. Hybrid Algorithm Simulation

1. Trimf Membership Function Type

Trimf membership function training process use hybrid algorithm, which is use epoch=100 and get RMSE score $2.3693 \mathrm{e}-06$. 


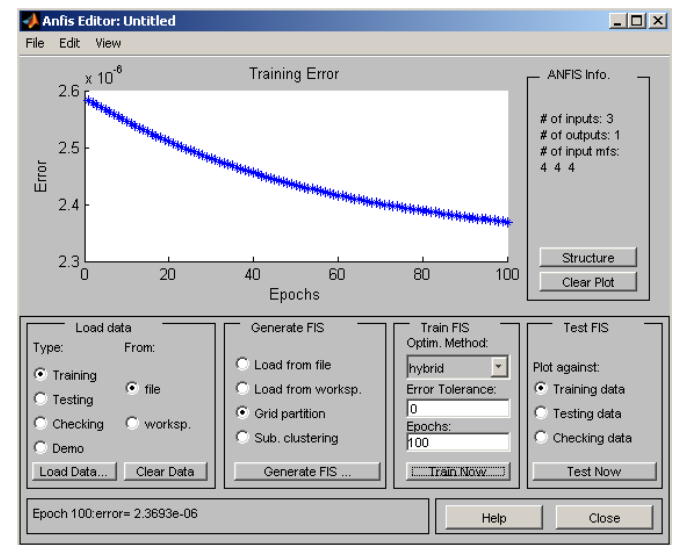

Figure 4. Trimf Hybrid Algorithm Training

Trimf membership function testing process use hybrid algorithm, which is use epoch=100 and get RMSE score $2.5327 \mathrm{e}-06$.

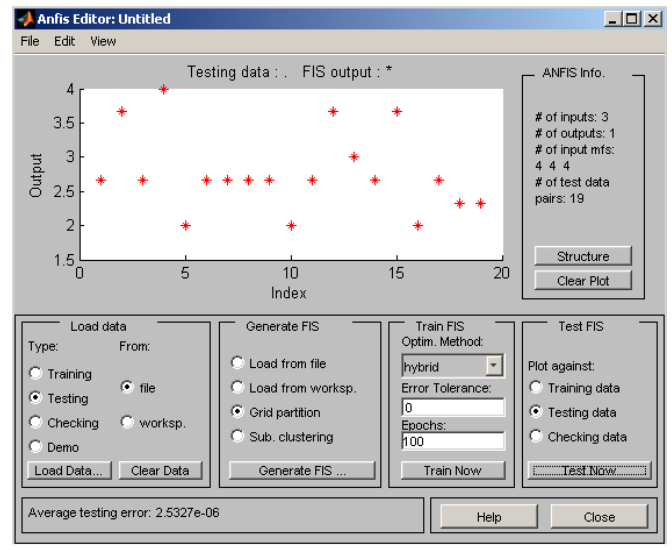

Figure 5. Trimf Hybrid Algorithm Testing

2. Trapmf Membership Function Type

Trapmf membership function training process use hybrid algorithm, which is use epoch=100 and get RMSE score 2.582e-06.

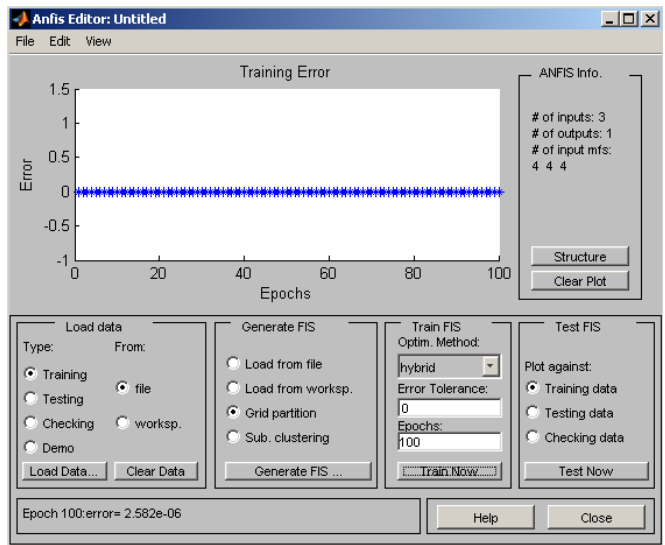

Figure 6. Trapmf Hybrid Algorithm Training

Trapmf membership function testing process use hybrid algorithm, which is use epoch=100 and get RMSE score 2.8324e-06.

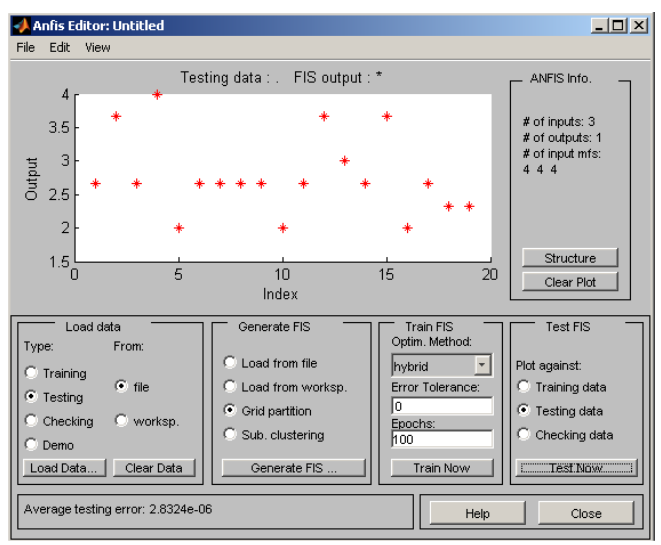

Figure 7. Trapmf Hybrid Algorithm Testing

3. Gbellmf Membership Function Type

Gbellmf membership function training process use hybrid algorithm, which is use epoch $=100$ and get RMSE score 2.4857e-06. 


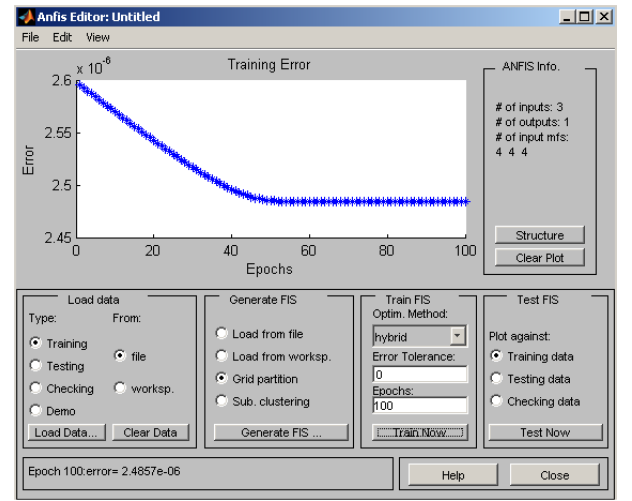

Figure 8. Gbellmf Hybrid Algorithm Training

Gbellmf membership function testing process use hybrid algorithm, which is use epoch=100 and get RMSE score 2.7573e-06.

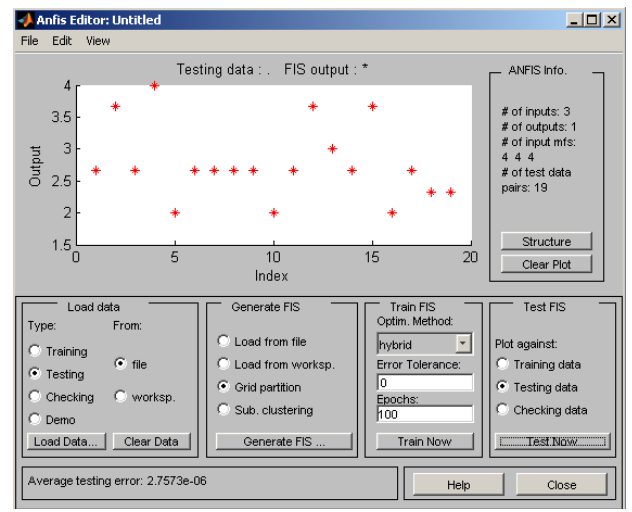

Figure 9. Gbellmf Hybrid Algorithm Testing

4. Gaussmf Membership Function Type

Gaussmf membership function training process use hybrid algorithm, which is use epoch $=100$ and get RMSE score 2.4987e-06.

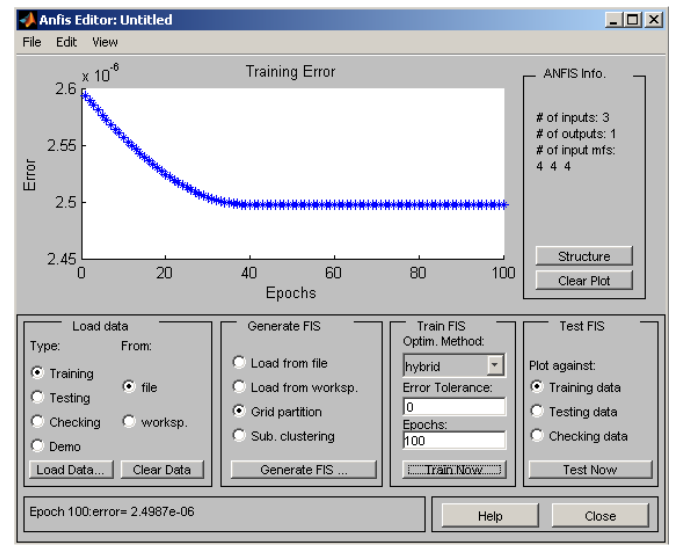

Figure 10. Gaussmf Hybrid Algorithm Training

Gaussmf membership function testing process use hybrid algorithm, which is use epoch=100 and get RMSE score 2.8324.

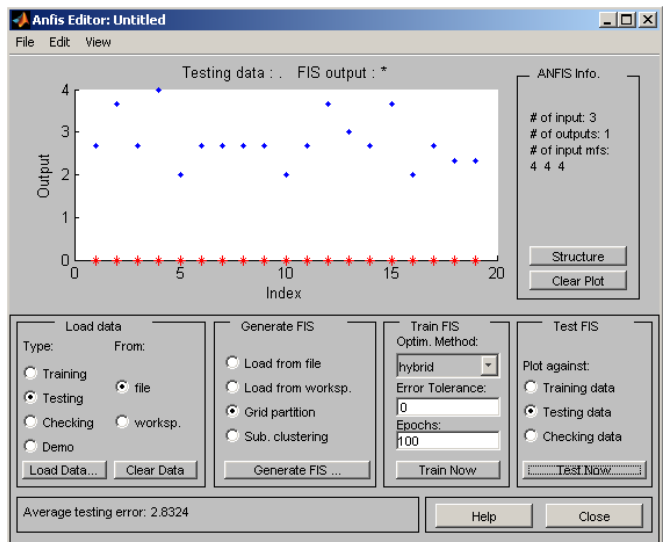

Figure 11. Gaussmf Hybrid Algorithm Testing

B. Back Propagation Algorithm Simulation

1. Trimf Membership Function Type

Trimf membership function training process use back propagation algorithm, which is use epoch $=100$ and get RMSE score 2.3322 .

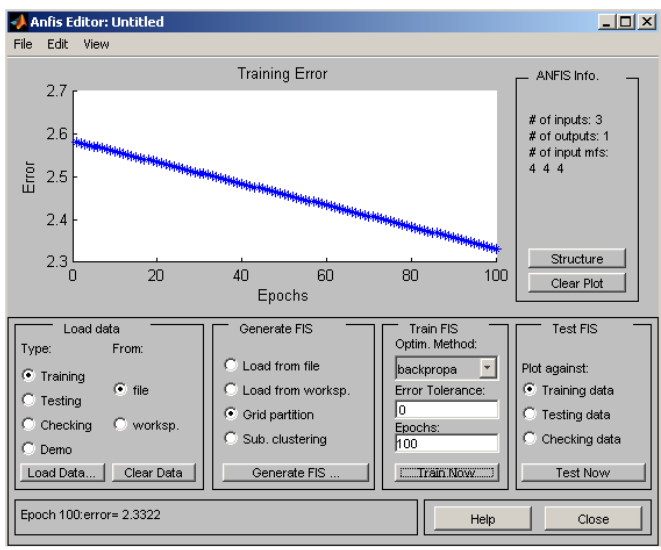

Figure 12. Trimf Back propagation Algorithm Training

Trimf membership function testing process use back propagation algorithm, which is use epoch $=100$ and get RMSE score 2.5546. 


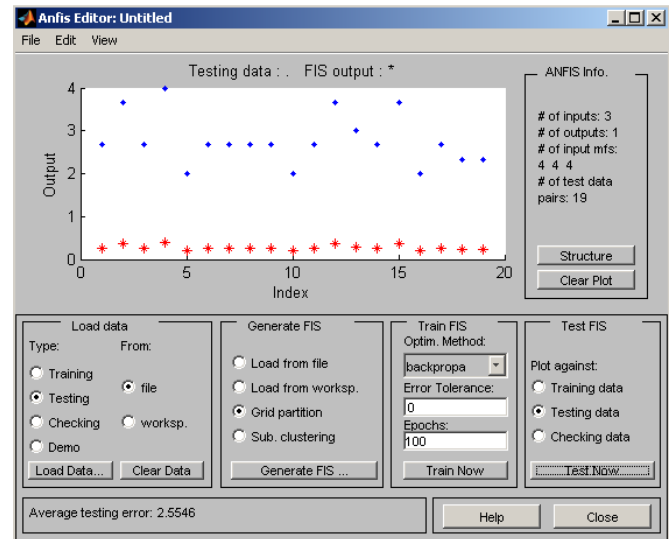

Figure 13. Trimf Back propagation Algorithm Testing

\section{Trapmf Membership Function Type}

Trapmf membership function training process use back propagation algorithm, which is use epoch $=100$ and get RMSE score 2.3345.

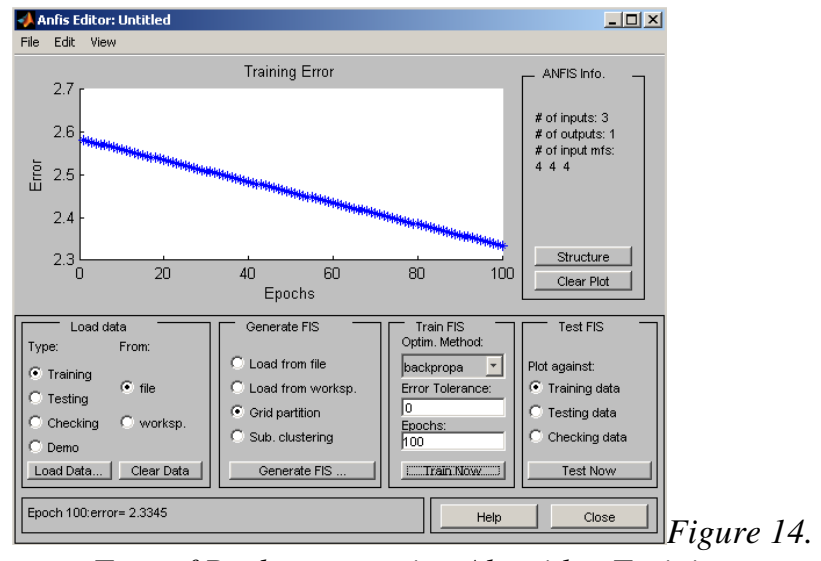

Trapmf Back propagation Algorithm Training

Trapmf membership function testing process use back propagation algorithm, which is use epoch $=100$ and get RMSE score 2.5581 .

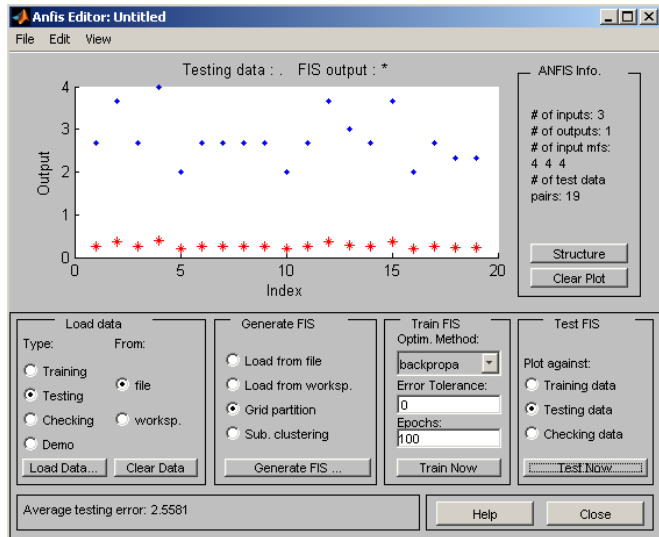

Figure 15. Trapmf Back propagation Algorithm Testing

3. Gbellmf Membership Function Type

Gbellmf membership function training process use back propagation algorithm, which is use epoch $=100$ and get RMSE score 2.3343.

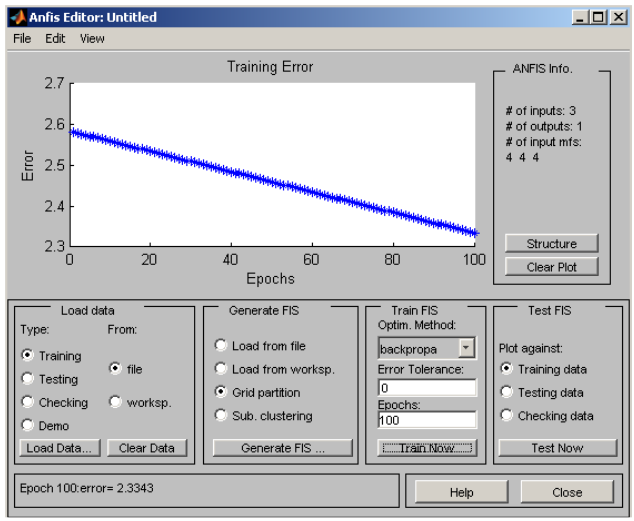

Figure 16. Gbellmf Back propagation Algorithm Training

Gbellmf membership function testing process use back propagation algorithm, which is use epoch $=100$ and get RMSE score 2.5587. 


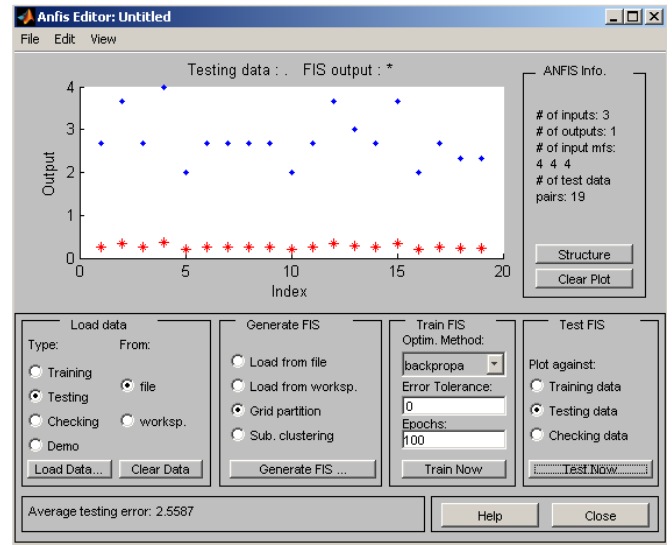

Figure 17. Gbellmf Back propagation Algorithm Testing

4. Gaussmf Membership Function Type

Gaussmf membership function training process use back propagation algorithm, which is use epoch $=100$ and get

RMSE score 2.333

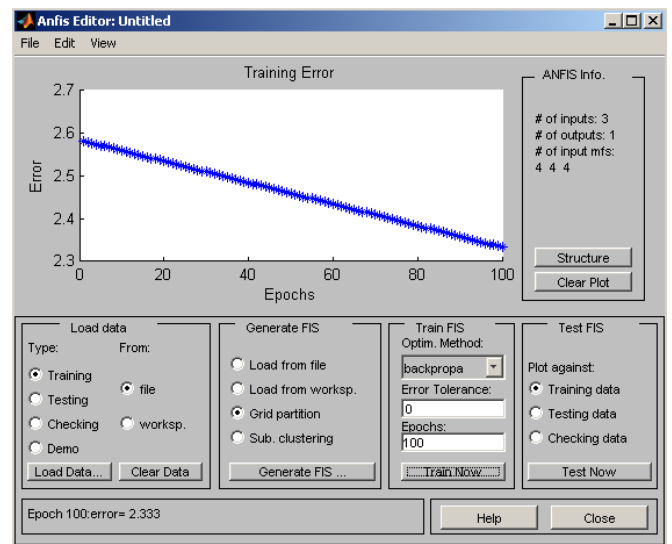

Figure 18. Gaussmf Back propagation Algorithm Training

Gaussmf membership function testing process use back propagation algorithm, which is use epoch $=100$ and get RMSE score 2.5567.

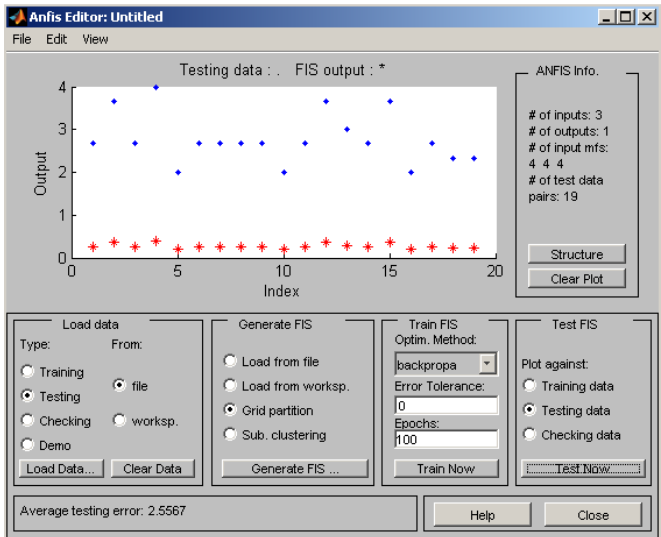

Figure 19. Gaussmf Back propagation Algorithm Testing

C. Result Testing

Based on previous testing on both data training and data testing with trimf, trapmf, gbellmf, and gaussmf membership functions with constant output and use hybrid algorithm and back propagation algorithm, it can be seen from Table 1 for the result of those test.

Table 1. Comparison between Data Training and Hybrid Algorithm and Back Propagation Testing

\begin{tabular}{|c|c|c|c|c|c|}
\hline \multirow[t]{4}{*}{ No } & \multirow[t]{4}{*}{ Curves } & \multicolumn{4}{|c|}{ Algorithm } \\
\hline & & \multicolumn{2}{|c|}{ Hybrid } & \multicolumn{2}{|c|}{ Backpropagation } \\
\hline & & \multicolumn{4}{|c|}{ Constant } \\
\hline & & Training & Testing & Training & Testing \\
\hline 1 & Trimf & $2.3693 \mathrm{e}-06$ & $2.5327 \mathrm{e}-06$ & 2.3322 & 2.5546 \\
\hline 2 & Trapmf & $2.582 \mathrm{e}-06$ & $2.8324 \mathrm{e}-06$ & 2.3345 & 2.5581 \\
\hline 3 & Gbellmf & $2.4857 \mathrm{e}-06$ & $2.7573 \mathrm{e}-06$ & 2.3343 & 2.5587 \\
\hline 4 & Gaussmf & $2.4987 \mathrm{e}-06$ & 2.8324 & 2.333 & 2.5567 \\
\hline
\end{tabular}

D. Graphical User Interface (GUI)

Figure 20 shows the result from using matlab 2013b software. 


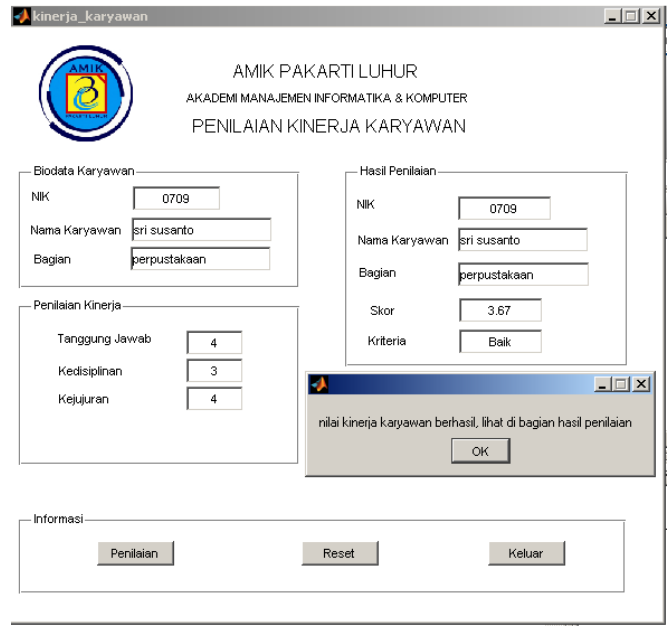

Figure 20. EPV Display GUI

E. Software Quality Assurance (SQA)

Questionnaires that had been given to 5 respondents related to EPV.

Table 2. SQA Metric Questionnaire Result

\begin{tabular}{|l|l|l|l|l|l|l|l|l|l|}
\hline \multirow{2}{*}{ User } & \multicolumn{7}{|c|}{ Metric SQA } & \multirow{2}{*}{ Score } \\
\cline { 2 - 9 } & 1 & 2 & 3 & 4 & 5 & 6 & 7 & 8 & \\
\hline 1 & 7 & 8 & 8 & 8 & 9 & 9 & 8 & 9 & 85.5 \\
& 5 & 5 & 5 & 0 & 0 & 0 & 5 & 0 & \\
\hline 2 & 8 & 8 & 8 & 8 & 9 & 9 & 8 & 9 & 86 \\
& 5 & 5 & 0 & 0 & 0 & 0 & 5 & 0 & \\
\hline 3 & 8 & 8 & 8 & 8 & 9 & 9 & 8 & 9 & 86 \\
& 0 & 5 & 0 & 5 & 0 & 0 & 5 & 0 & \\
\hline 4 & 8 & 8 & 8 & 8 & 9 & 9 & 8 & 9 & 86 \\
& 5 & 5 & 0 & 0 & 0 & 0 & 5 & 0 & \\
\hline 5 & 8 & 8 & 8 & 8 & 9 & 9 & 9 & 9 & 86.5 \\
& 0 & 5 & 0 & 0 & 0 & 0 & 0 & 0 & \\
\hline
\end{tabular}

\section{CONCLUSIONS RECOMMENDATIONS}

AND

Based on the ANFIS research model on employee performance, there are some conclusions to be made in this reseach:

1. A hybrid algorithm has a high accuracy with various mf types compared with back propagation algorithm.

2. The model is considered the best if it produces the smallest RSME error rate. Therefore, this research use hybrid model with mf trimf type, which is this is the best model with the result RSME 2.3693ee-06.

3. The result of feasibility of the software is optimal, which is the result of SQA is 86, more than its minimum optimal standard SQA 80.
Recommendations that can be given through the results of this research in order to get better results for further research, as follows:

1. It is recommended to test some types of association functions, not only trimf, trapmf, gbellmf, and gaussmf, but also the numbers of association function to obtain varied test results.

2. It is recommended to develop FIS method for employee performance research in order to get comparison of the test result between FIS and ANFIS.

3. It is recommended for further research so that the output produced is not only to become employee performance in internal management scale, but also reported to external such as Kopertis and PakartiLuhur foundation.

\section{REFERENCES}

[1] Goleman, Daniel. 2000. Emotional Intelligence (terjemahan). Jakata: PT GramediaPustakaUtama.

[2] Kusumadewi, S., Sri H. 2010, Neuro Fuzzy IntegrasiSistem Fuzzy \&JaringanSyarafEdisi 2. GrahaIlmu Yogyakarta

[3] Mathis, R.L., J.H. Jackso. 2006, Human Resource Management: ManajemenSumberDayaManusia. Terjemahan Dian Angelia. Jakarta: SalembaEmpat.

[4] Pathania, D. K. dan A. D. Pathak. 2011, Effectiveness of Performance Appraisal System of Insurance Sector - A Study of Himachal Pradesh. Gurukul Business Review (GBR).

[5] Prabowo, W. P., Rahmadya, T. 2012, Penerapan Soft Computing DenganMATLAB.RekayasaSains Bandung.

[6] Sri KusumaDewi, Hartati. 2010, Neuro Fuzzy, IntegrasiSistem Fuzzy danJaringanSyaraf, Yogyakarta: GrahaIlmu.

[7] Widodo, PudjoPrabowo, et al. (2013). Penerapan Data Mining dengan MATLAB. Bandung: RekayasaSains. 